\title{
Review: vaccination reduces the incidence of serologically confirmed influenza in healthy adults
}

Demicheli V, Rivetti D, Deeks JJ, et al. Vaccines for preventing influenza in healthy adults. Cochrane Database Syst Rev 2004;(3):CD001269.

\section{$Q$ Is vaccination effective for reducing the incidence of influenza in healthy people 14-60 years of age?}

\section{METHODS}

Data sources: Cochrane Central Register of Controlled Trials
(Cochrane Library, Issue 1, 2004), MEDLINE (1966-2003),
EMBASE/Excerpta Medica (1990-2003), bibliographies of
relevant articles, and manufacturers and researchers.
$\begin{aligned} & \text { Study selection and assessment: controlled trials (published in } \\ & \text { any language) that evaluated the effectiveness of influenza } \\ & \text { vaccines for protection from exposure to naturally occurring } \\ & \text { influenza in healthy people 14-60 years of age. }\end{aligned}$
$\begin{aligned} & \text { Outcomes: incidence of clinically defined influenza (CDI) } \\ & \text { (unspecified or specified on the basis of specific symptoms or } \\ & \text { signs) and serologically confirmed influenza (SCI). }\end{aligned}$

\section{MAIN RESULTS}

47 trials ( 25 randomised controlled trials [RCTs], $\mathrm{n}=59$ 566) met the selection criteria. (1) Influenza vaccine (inactivated parenteral vaccine $[I P]$, live aerosol vaccine [LA], or inactivated aerosol vaccine [IA]) $v$ placebo. Rates of CDI and SCI were lower in the IP group than in the placebo group (table). Rates of specified CDI and SCI were also lower in the LA group than in the placebo group (table). The rate of unspecified CDI was lower in the IA group than in the placebo group (table). (2) $\geqslant 1$ vaccine recommended for that year $v$ placebo or other vaccines. The rate of CDI was lower in the vaccine group (IP, LA, and IA groups combined) than in the placebo groups (27 trials; relative risk reduction [RRR] $22 \%, 95 \%$ CI 14 to 30 ). The rate of SCI was lower in the combined IP and LA group than in the control group (placebo or non-influenza vaccine) (2l trials; RRR 68\%, CI 57 to 76). (3) Vaccines matching circulating strains $v$ placebo or other vaccines. The rate of CDI was lower in the vaccine group (IP, LA, and IA groups combined) than in the placebo group ( 16 trials; RRR 33\%, CI 20 to 44). Overall the rate of SCI was lower in the combined vaccine group than in the control group ( 13 trials; RRR 75\%, CI 62 to 84). For correspondence: Dr V Demicheli, Servizo Sovrazonale di Epidemiologia Piemonte, Italy. demichelivittorio@asl20.piemonte.it

Source of funding: Ministry of Defence, UK.

\section{CONCLUSIONS}

In healthy people 14-60 years of age, vaccines are effective for reducing the incidence of serologically confirmed influenza. However, they are not as effective for reducing the incidence of clinically defined influenza.

A modified version of this abstract appears in ACP Journal Club.

Commentary

$\mathrm{N}$ umerous studies have evaluated the effects of influenza immunisation on school or work absences, emergency department visits, and hospital admissions in healthy volunteers, but no review has aggregated the results of these investigations. The systematic review by Demicheli et al is especially important given that mass influenza vaccination programmes are currently under consideration, or even being offered, in some jurisdictions (eg, Ontario, Canada).

Demicheli et al conclude that influenza vaccines are effective in reducing the incidence of $\mathrm{SCl}$. In addition, they found a significant, albeit small, reduction in time off work among people who were vaccinated. In the event of a pandemic, similar findings would have a much greater effect. Indeed, it may be worthwhile to consider universal immunisation to further evaluate such findings in larger populations. However, vaccination does not seem to be as effective in reducing the occurrence of CDI. It is noteworthy that most of the included studies were conducted in the 1970s. Important changes in provider attitudes and public awareness, acceptance, and demand for the vaccine have likely occurred over the past 30 years. Preparation for a potential influenza pandemic has been identified as a priority by healthcare planners and has focused efforts on improving the prediction of circulating influenza strains and enhancing the manufacture of vaccine to ensure adequate supply.

The results of the review by Demicheli et al are relevant to primary care nurses and nurse practitioners, public health nurses, communicable disease specialists, and particularly, to community healthcare planners. The findings raise thought provoking and relevant questions about the efficacy of wide scale influenza immunisation.

Toula M Gerace RN, MSc Byron Family Medical Centre of London Health Sciences Centre University of Western Ontario London, Ontario, Canada

Influenza vaccines (inactivated parenteral vaccine [IP], live aerosol vaccine $[\mathrm{LA}]$, or inactivated aerosol vaccine [IA]) $v$ placebo for preventing influenza in healthy persons $14-60$ years of age at a mean follow up of 87 days*

\begin{tabular}{|c|c|c|c|c|c|}
\hline Outcome & Number of trials (n) & Comparison & Weighted event rates & $\operatorname{RRR}(95 \% \mathrm{Cl}) \dagger$ & NNT (Cl) \\
\hline CDI unspecified & $\begin{array}{l}8(6566) \\
2(438)\end{array}$ & $\begin{array}{l}\text { IP v placebo } \\
\text { IA v placebo }\end{array}$ & $\begin{array}{r}17 \% \text { v } 21 \% \\
7 \% \text { v } 20 \%\end{array}$ & $\begin{array}{l}31 \%(5 \text { to } 51) \\
65 \%(32 \text { to } 82)\end{array}$ & $\begin{array}{l}25(13 \text { to } \infty) \\
8(4 \text { to } 50)\end{array}$ \\
\hline CDI specified & $\begin{array}{l}10(4271) \\
2(4591) \\
2(1069)\end{array}$ & $\begin{array}{l}\text { IP } v \text { placebo } \\
\text { LA v placebo } \\
\text { IA } v \text { placebo }\end{array}$ & $\begin{array}{l}36 \% \text { v } 44 \% \\
20 \% \text { v } 23 \% \\
20 \% \text { v } 28 \%\end{array}$ & $\begin{array}{l}22 \%(9 \text { to } 33) \\
15 \%(5 \text { to } 24) \\
27 \%(0 \text { to } 47)\end{array}$ & $\begin{array}{l}12(7 \text { to } 34) \\
34(17 \text { to } 100) \\
17(7 \text { to } \infty)\end{array}$ \\
\hline $\mathrm{SCl}$ & $\begin{array}{l}9(2411) \\
2(427)\end{array}$ & $\begin{array}{l}\text { IP } v \text { placebo } \\
\text { LA } v \text { placebo }\end{array}$ & $\begin{array}{l}2 \% \vee 8 \% \\
0.5 \% \vee 8.5 \%\end{array}$ & $\begin{array}{l}67 \%(51 \text { to } 78) \\
79 \%(44 \text { to } 92)\end{array}$ & $\begin{array}{l}17(13 \text { to } 34) \\
13(6 \text { to } \infty)\end{array}$ \\
\hline
\end{tabular}

${ }^{*} \mathrm{CDI}=$ clinically defined influenza; $\mathrm{SCl}=$ serologically confirmed influenza. Other abbreviations defined in glossary; weighted event rates, $\mathrm{NNT}$, and $\mathrm{Cl}$ calculated from data in article using a random effects model.

tRRR is referred to as vaccine efficacy in the original Cochrane review. 